\title{
PENGGUNAAN BAHASA IKLAN PADA PAPAN REKLAME (STUDI SURVEI SEPANJANG KAMPUNG RAMBUTAN SAMPAI DENGAN LEBAK BULUS)
}

\author{
Yulia Agustin; Hilda Hilaliyah; Syarifudin Yunus \\ Program Studi Pendidikan Bahasa dan Sastra Indonesia \\ Fakultas Bahasa dan Seni, Universitas Indraprasta PGRI \\ Jakarta \\ Pos-el: yuliaagustin.unindra@gmail.com
}

\begin{abstract}
Language ofadvertisingis growing rapidly, including in thebillboard. In fact, there are manybillboardsusing languagedoes notmeet the rules. Survey conductedonthe mainroadbetweenKampungRambutantoLebak Bulusobtainedthe standardlanguageadsonbillboardsisverylow, only5.5\% andnon-standardlanguageadsreached $94.5 \%$. Non-standardlanguage ofadvertisingis dominatedwith1) the dominance ofphrase, 2) neglect ofsyntagmaticrelationships, 3) thevanished sentencefunction, 4) the effect ofdialect, 5) the influence ofa foreignlanguage, 6) spellingmistakes, 7) ambiguity, and8) waiverconjunctions.From theaspect oflanguagestructure, dominatedby thepersuasivestructure $4 \%$, poweredmovement $22 \%$, evocative $17 \%$, andinformative $17 \%$.
\end{abstract}

Keywords: advertisement language, billboards

\begin{abstract}
ABSTRAK
Bahasa iklan berkembang pesat dalam pemakaiannya. Salah satunya digunakan pada papan reklame. Pada kenyataannya, masih banyak penggunaan bahasa iklan papan reklame yang tidak memenuhi kaidah bahasa. Survei yang dilakukan pada jalan utama antara Kampung Rambutan sampai dengan Lebak Bulus diperoleh aspek kebakuan bahasa iklan pada papan reklame tergo9long sangat rendah, hanya 5,5\% dan bahasa iklan yang tidak baku mencapai 94,5\%. Ketidakbakuan bahasa iklan lebih didominasi oleh 1) pemakaian frasa, 2) pengabaian hubungan sintagmatik, 3) adanyapelesapan fungsi kalimat, 4) pengaruh dialek, 5) pengaruh bahasa asing, 6) kesalahan ejaan, 7) ambiguitas, dan 8) pengabaian konjungsi. Dari aspek struktur bahasanya, lebih didominasi oleh struktur persuasif 44\%, bertenaga gerak $22 \%$, menggugah $17 \%$, dan informatif $17 \%$.
\end{abstract}

Kata kunci: bahasa iklan, papan reklame

\section{PENDAHULUAN}

Media komunikasi dari tahun ke tahun semakin maju pesat. Peningkatan media komunikasi tidak hanya terjadi pada media massa seperti radio, televisi, dan media 
cetak, tetapi juga terjadi pada pemanfaatan jejaring sosial, teknologi internet, dan media promosi seperti papan reklame. Sebagai salah satu media promosi, keberadaan papan reklame sering kita jumpai di pinggir jalan untuk mempromosikan suatu produk tertentu. Papan reklame merupakan media yang menggunakan bahasa iklan untuk membujuk dan memengaruhi pembacanya.

Bahasa merupakan kekuatan utama pada media papan reklame. Namun, penggunaan bahasa pada papan reklame belum sesuai dengan kaidah berbahasa Indonesia. Sejauh ini, belum banyak penelitian yang mengungkap penggunaan bahasa iklan pada papan reklame. Bahasa iklan pada dasarnya dapat memberi pengaruh terhadap perilaku berbahasa secara praktis pada masyarakat. Bahkan, bahasa iklan dapat membentuk kebiasaan berbahasa masyarakat.

Di sisi lain, bahasa iklan pada papan reklame seharusnya disusun dengan memperhatikan kaidah berbahasa yang baik dan benar tanpa mengenyampingkan tujuan komunikasi untuk memengaruhi pembaca. Bahasa iklan seharusnya tetap disusun dengan kalimat yang baik, benar, dan menarik. Dengan demkian, bahasa iklan akan memberi manfaat terhadap pembelajaran bahasa yang positif.

Pengaruh bahasa iklan terhadap masyarakat sangatlah besar. Masyarakat banyak menggunakan jargon yang dikembangkan dari media massa; seperti 'kembali ke laptop', "bukan basa basi', "apapun makanannya, minumnya ....". Hal ini menunjukkan bahwa bahasa iklan mudah melekat dalam ingatan masyarakat. Oleh karena itu, upaya untuk mendeteksi kesalahan berbahasa dan sekaligus upaya memperbaikinya harus dilakukan. Salah satunya melalui penelitian bahasa iklan yang tersebar di berbagai wilayah di Jakarta. Atas dasar itu, kajian tentang Penggunaan Bahasa Iklan pada Papan Reklame (Studi Survei Sepanjang Kampung Rambutan sampai dengan Lebak Bulus) menarik untuk dilakukan.

\section{METODE PENELITIAN}

\section{Metode}

Metode yang digunakan adalah metode deskriptif. Metode deskriptif adalah suatu metode dalam meneliti status sekelompok manusia, suatu objek, suatu set kondisi, suatu sistem pemikiran, ataupun suatu kelas peristiwa pada masa sekarang (Nazir, 2009:54). Tujuan dari penelitian deskriptif ini adalah untuk membuat deskripsi, gambaran atau lukisan secara sistematis, faktual dan akurat mengenai fakta-fakta, sifat-sifat serta hubungan antarfenomena yang diselidiki. Pemakaian bahasa dalam iklan menuntut suatu wilayah (dalam hal ini Kampung Rambutan sampai dengan Lebak Bulus) agar bahasa itu dapat berfungsi sebagai sarana komunikasi yang dapat mencapai sasaran yang dikehendaki secara baik.

\section{Sumber Data}

Sumber data penelitian ini adalah papan reklame yang tersebar di sepanjang jalan Kampung Rambutan sampai Lebak Bulus. Data meliputi reklame-reklame semua produk. Data dikumpulkan dengan teknik catat, yaitu mencatat semua data yang ditemui di lapangan (atau dengan kata lain mencatat penggunaan bahasa dalam reklame di sepanjang jalan Kampung Rambutan sampai Lebak Bulus). 


\section{Instrumen Penelitian}

Dalam penelitian ini, instrumen penelitian merupakan peneliti (subjek) yang menempatkan dirinya sebagai alat untuk mengetahui dan melakukan pendalaman terhadap pencarian sumber data yang dibutuhkan yaitu bahasa iklan pada papan reklame yang terdapat pada jalan utama antara Kampung Rambutan sampai dengan Lebak Bulus.

\section{Metode Analisis Data}

Metode analisis data penelitian ini dilakukan dengan pengelompokan/klasifikasi data dengan melihat kesamaan model atau tipe-tipe penggunaan bahasanya serta mengklasifikasikan struktur bahasa yang digunakan dalam reklame tersebut.

Analisis yang dilakukan terhadap bahasa iklan pada papan reklame yang terdapat pada jalan utama antara Kampung Rambutan sampai dengan Lebak Bulus difokuskan pada beberapa aspek yang terkait dengan keberadaan satuan bahasa sebagai alat komunikasi seperti berikut.

a. Aspek kebakuan bahasa yang digunakan, yang terdiri dari: 1) pelesapan fungsi kalimat, 2) kesalahan ejaan, 3) pengaruh dialek, 4) dominasi frase/klausa, 5) pengabaian hubungan sintagmatik, 6) pengaruh bahasa asing, 7) ambiguitas, dan 8) pengabaian konjungsi. Papan reklame sebagai salah satu bentuk bahasa iklan pada dasarnya tidak dapat dilepaskan dari aspek kebakuan bahasa. Dalam kaitan itu, bahasa yang baku adalah bahasa yang standar dipakai dengan tingkat keberterimaan di masyarakat yang tinggi. Terkadang bahasa yang baku yang dianut berdasar pada ragam bahasa yang digunakan, yang dianggap memiliki kelengkapan kaidah-kaidah bahasa yang baku.

1) Pelesapan fungsi kalimat terjadi karena tidak adanya salah satu fungsi kalimat dalam susunan bahasa iklan pada papan reklame yang berbentuk sebagai struktur bangun kalimat. Pelesapan fungsi kalimat dapat berupa fungsi subjek $(\mathrm{S})$, predikat $(\mathrm{P})$, atau objek $(\mathrm{O})$. Bahasa iklan lebih cenderung menggunakan satuan bahasa berbentuk frase atau klausa tanpa memperhatikan kehadiran fungsi kalimat yang menjadi dasar dalam pemaknaan bahasa iklan.

2) Kesalahan ejaan terjadi karena diabaikan kaidah penggunaan ejaan atau tanda baca dalam penyusunan bahasa iklan pada papan reklame sehingga dapat menjadi contoh bahasa yang tidak baku.

3) Pengaruh dialek terjadi karena adanya intervensi penggunaan kata-kata dalam bahasa daerah tertentu, khususnya dialek Jakarta. Papan reklame yang menggunakan dialek dapat merancukan komposisi penggunaan bahasa iklan. 
4) Dominasi frase atau klausa terjadi karena penggunaan bahasa iklan pada papan reklame berbentuk frase atau klausa sehingga bahasa iklan yang digunakan belum lengkap sebagai satuan bahasa yang bermakna. Frase atau klausa merupakan satuan sintaksis yang tidak memiliki makna. Setiap frase atau klausa seharusnya disertai satuan bahasa lain yang dapat membentuk kalimat.

5) Hubungan sintagmatik terjadi karena adanya bentuk bahasa iklan berupa kalimat yang mengisyaratkan adanya hubungan peristiwa atau kejadian yang satu dengan bahasa yang mengikutinya. Hubungan sintagmatik menekankan adanya keterkaitan satuan bahasa iklan dengan teks sebelum atau sesudahnya sehingga dapat dipahami sebagai satuan bahasa yang memiliki makna.

6) Pengaruh bahasa asing terjadi karena penyusunan bahasa iklan pada papan reklame yang dipengaruhi oleh penggunaan kata-kata bahasa asing dalam struktur bahasa Indonesia. Kondisi menyiratkan adanya interferensi bahasa iklan.

7) Ambiguitas terjadi karena adanya bentuk penggunaan satuan bahasa yang bersifat ambigu atau bermakna ganda. Kata-kata yang ambigu pada papan reklame dapat menimbulkan makna yang tidak jelas atau berbeda dari makna yang diharapkan dalam teks bahasa iklan. Ambiguitas merupakan gejala bahasa yang dapat menimbulkan perbedaan makna terhadap konteks kalimat yang sama akibat pemakaian kata yang rancu.

8) Pengabaian konjungsiterjadi karena adanya pengabaian pemakaian kata penghubung atau konjungsi antarkalimat yang menyatakan adanya hubungan sebab-akibat.

b. Aspek struktur bahasa iklan, 1) menggugah, 2) informatif, 3) persuasif, dan 4) bertenaga gerak. Reklame sebagai salah satu bentuk bahasa iklan dituntut mampu menggugah, menarik, mengidentifikasi, menggalang kebersamaan, dan mengkombinasikan pesan dengan komparatif kepada khalayak (Rapp \& Collins, 1995:152).

1. Menggugah bertumpu pada struktur penggunaan bahasa iklan pada papan reklame yang bersifat mencermati kebutuhan konsumen, memberikan solusi, dan memberikan perhatian.

2. Informatif bertumpu pada struktur penggunaan bahasa iklan pada papan reklame yang ditandai dengan penggunaan kata-kata yang lugas atau jelas, bersahabat, dan komunikatif. Bahasa yang digunakan tidak berteletele. 
3. Persuasif bertumpu pada struktur penggunaan bahasa iklan pada papan reklame yang menyajikan rangkaian kalimat atau kata yang dapat membuat konsumen nyaman, senang, tenteram, dan menghibur.

4. Bertenaga gerak bertumpu pada struktur penggunaan bahasa iklan pada papan reklame yang memiliki komposisi kata-kata yang mengisyaratkan untuk dilakukan dan dapat dimanfaatkan selama masa penawaran/masa promosi berlangsung.

Mengacu pada teks bahasa iklan pada papan reklame yang terdapat pada jalan utama antara Kampung Rambutan sampai dengan Lebak Bulus yang menjadi objek penelitian kemudian dilakukan analisis terhadap satuan bahasa yang digunakan, baik dalam bentuk kata maupun kalimat.

\section{HASIL DAN PEMBAHASAN}

Iklan adalah bentuk komunikasi khusus yang bersifat membujuk masyarakat agar tertarik terhadap barang atau jasa yang ditawarkan. Jefkins ( dalam Kasali, 2007: 9) mengatakan bahwa iklan adalah pesan yang menawarkan suatu produk yang ditujukan kepada masyarakat lewat suatu media. Iklan diarahkan untuk membujuk orang supaya membeli, "advertising aims to persuade people to buy". Omar ( dalam Arifin, 2014: 63) menyatakan bahwa iklan merupakan salah satu bentuk komunikasi, baik secara lisan maupun tulisan yang berisi sesuatu yang disuguhkan, ditawarkan, atau yang dijual agar menarik pembacanya. Pendapat tersebut, sejalan dengan Rachmadi (1993:37) yang mengungkapkan "Iklan adalah komunikasi persuasif yang mengajak calon pembeli untuk menerima citra sebagaimana yang ditayangkan. Melalui penginterpretasian kualitas produk dan jasa yang dituangkan dalam pesan iklan, diharapkan masyarakat dapat menerima pesan tersebut dengan baik, kemudian melakukan tindakan seperti yang diharapkan oleh pemasang iklan. Tindakan tersebut tentu saja tindakan membeli produk yang ditawarkan". Iklan adalah berita pesanan (untuk mendorong, membujuk) tentang barang atau jasa yang ditawarkan. Mempromosikan suatu barang melalui iklan bukanlah hal yang mudah. Dibutuhkan pesan yang singkat tetapi maknanya mudah dipahami oleh konsumen. Hal ini bertujuan agar konsumen terdorong untuk membeli produk yang ditawarkan (Tim Penyusun Kamus Besar Bahasa Indonesia, 2008:521)

Menurut Sandage (dalam Shimp, 2000: 38), periklanan adalah penyebaran informasi tentang ide atau jasa atau produk untuk mendorong tindakan yang sesuai dengan yang diharapkan pemasang iklan, sedangkan pengertian periklanan menurut Committee of American Marketing Association adalah tiap bentuk pembayaran presentasi yang bersifat nonpersonal untuk mempromosikan suatu gagasan, barang, 
atau jasa yang dibayar oleh sponsor yang jelas. Dengan demikian, melalui penginterpretasian kualitas produk dan jasa yang dituangkan dalam pesan iklan, masyarakat diharapkan dapat menerima pesan tersebut dengan baik kemudian melakukan tindakan seperti yang diharapkan oleh pemasang iklan.

Secara umum, periklanan memiliki beberapa fungsi yaitu pemberi informasi, persuasi, pengingat, penambah nilai, dan pendamping produk (Suyatno, 2004: 56). Namun, yang lebih nyata adalah fungsi persuasif. Iklan dapat dikatakan sebagai suatu bentuk komunikasi yang persuasif karena iklan seringkali dikembangkan dengan menstimulus tanda dan simbol yang berkaitan dengan emosi dan sejenisnya (Aaker dan Myers dalam Ritonga, 2005: 73)

Tentangbahasaiklan, Jefkins (1997:228) mengungkapkan bahwa teks iklan yang memiliki karakteristik, orisinal, dan persuasif dapat tercipta jika memenuhi syaratsyarat sebagai berikut. a)Teks iklan yang ditulis harus bersifat menjual, meskipun iklan hanya bertujuan untuk mengingatkan saja, b) Rahasia keberhasilan iklan adalah pengulangan (repetition), apakah pengulangan itu dengan memanfaatkan iklan secara kontinyu ataudengan menerapkan pengulangan dalam tubuh teks iklan itu sendiri, c) Orang tidak akan peduli untuk membaca teks iklan karena pesan iklan harus memanfaatkan secara maksimal kata-kata dan menyampaikan pesannya dengan segera, d) Jika pembaca merasa tidak familiar terhadap suatu kata yang asing, perhatian pembaca terhadap iklan tersebut akan hilang. Oleh karena itu, setiap kata yang digunakan harus mudah dipahami dan tidak ada kemungkinan untuk menimbulkan keraguan di benak pembaca, dan e) Kata-kata singkat, kalimat-kalimat pendek, paragraf yang tidak terlalu panjang membantu menyampaikan pesan iklan serta memudahkan pembaca untuk memahami dan mengerti maksud teks iklan itu dengan cepat.

Dilihat dari fakta bahwa iklan dapat menjangkau hampir semua anggota masyarakat dari segala usia, kelas sosial, wilayah, dan profesi yang berminat pada apa yang ditawarkan, maka keberhasilan sebuah iklan sangat bergantung pada kemahiran seseorang dalam menggunakan bahasa. Felicia (2003:381) mengatakan bahwa hal yang perlu ditandai dalam laras iklan adalah bahwa kita tidak perlu selalu menggunakan kalimat lengkap. Ini berarti dalam membuat teks iklan tidak selalu digunakan kalimat yang mengandung subjek, predikat, objek, pelengkap, dan keterangan. Hal lain yang paling penting adalah keutuhan wacana. Seorang pembuat iklan harus mampu menciptakan kalimat tidak lengkap namun tidak menyalahi kaidah tatabahasa. Ketidaklengkapan kalimat dalam teks iklan ini merupakan usaha pembuat iklan untuk menarik perhatian dan menciptakan teks yang singkat dan berisi. Ini juga berarti bahwa kekakuan dalam bahasa iklan harus dihindari. Bahasa iklan harus menggunakan bahasa yang komuikatif dan tetap memperhatikan kaidah tatabahasa yang ada. 
Bahasa iklan pada umumnya terdiri atas kalimat-kalimat singkat. Penyingkatan tersebut dimaksudkan untuk menarik perhatian masyarakat. Selain itu, kalimatkalimat singkat dalam sebuah iklan berkaitan dengan biaya pembuatan iklan. Semakin banyak waktu dan tempat yang digunakan, semakin besar biaya yang diperlukan untuk membuat iklan.

Menulis dengan baik dan benar untuk keperluan iklan adalah pekerjaan yang tidak mudah. Isi teks iklan harus dapat memacu pembaca untuk menggabungkan beberapa imaji yang kadang tidak berkaitan secara langsung dengan barang yang ditawarkan. Teks iklan akan menjadi buruk jika penulis iklan tidak mampu bermain dengan kata-kata.

Salah satu bentuk iklan adalah papan reklame. Papan reklame adalah poster dalam ukuran besar yang dirancang oleh orang-orang yang melakukan perjalanan dengan kendaraan. Papan reklame adalah periklanan outdoor yang paling utama dan dirancang dengan tujuan memperkenalkan nama merek dan biasanya terpampang di jalan raya yang lalu lintasnya ramai (Suyatno, 2006:2)

Berkhouwer (dalam Winardi, 1980:9) menegaskan "Reklame adalah setiap pernyataan yang secara sadar ditujukan kepada publik dalam bentuk apapun juga yang dilakukan oleh seorang peserta lalu-lintas perniagaan yang diarahkan ke arah sasaran memperbesar penjualan barang-barang atau jasa-jasa yang berkepentingan dalam lalu-lintas perniagaan." Dengan demikian, dapat disimpulkan bahwa reklame adalah suatu iklan media cetak yang dipasang di tepi jalan guna untuk memberitahukan kepada khalayak tentang suatu barang yang ditulis secara singkat dan menggunakan logo yang sesuai jenis produk dengan harapan mampu menarik simpati pembaca untuk membelinya.

Berdasarkan survei yang dilakukan pada papan reklame yang terdapat pada jalan utama antara Kampung Rambutan sampai dengan Lebak Bulus setidaknya terdapat 30 reklame. Beberapa contoh bahasa iklan papan reklame tersebut adalah seperti berikut.
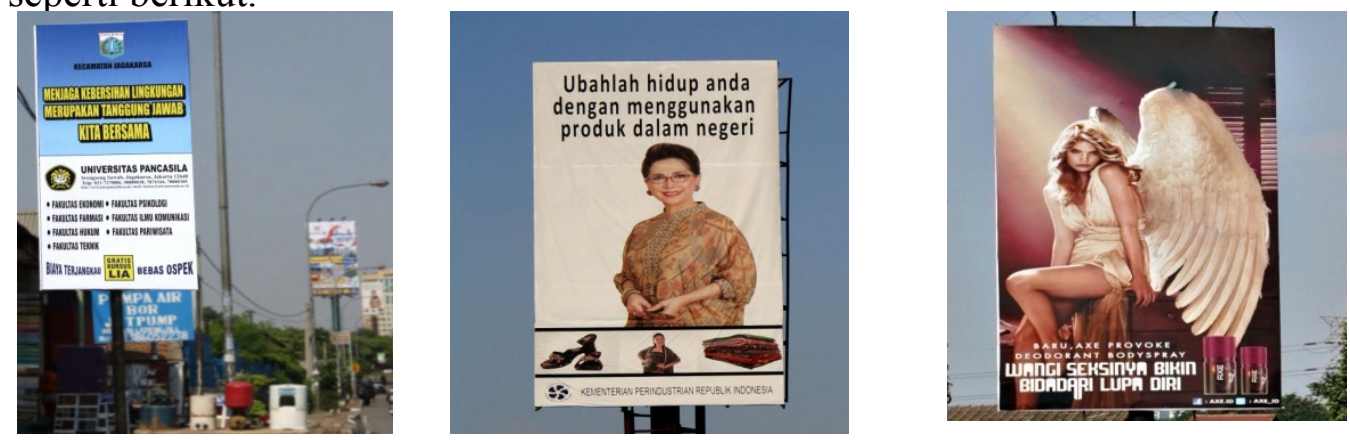

(Sumber: Koleksi Foto Erwan Setianto)

Pada dasarnya penggunaan bahasa iklan pada papan reklame yang terdapat pada jalan utama antara Kampung Rambutan sampai dengan Lebak Bulus dapat ditinjau berdasarkan: 
a. Aspek kebakuan bahasa yang digunakan, yang terdiri atas: 1) pelesapan fungsi kalimat, 2) kesalahan ejaan, 3) pengaruh dialek, 4) dominasi frase/klausa, 5) pengabaian hubungan sintagmatik, 6) pengaruh bahasa asing, 7) ambiguitas, dan 8) pengabaian konjungsi.

b. Aspek struktur bahasa iklan, yang bersifat 1) menggugah, 2) informatif, 3) persuasif, dan 4) bertenaga gerak.

Mengacu pada teks bahasa iklan pada papan reklame di lokasi tersebut, survei yang pernah dilakukan mendapati beberapa gejala seperti dalam tabel di bawah ini:

Data Bahasa Iklan

Analisis Bahasa

Struktur

Iklan

Bahasa Iklan

\section{MENJAGA KEBERSIHAN \\ LINGKUNGAN \\ MERUPAKAN TANGGUNG \\ JAWAB \\ KITA BERSAMA \\ Ubahlah hidup anda \\ dengan menggunakan \\ produk dalam negeri \\ WANGI SEKSINYA BIKIN \\ BIDADARI LUPA DIRI}

Aman, Sehat dan

Tidak Merepotkan

KEBANGGAAN

ATAS KARYA SEMPURNA

\section{NARKOBA, NO! SEHAT, YES!}

PAS di tangan, mudik jadi tenang

\begin{tabular}{|c|c|}
\hline $\begin{array}{l}\text { erjadinya pelesapan } \\
\text { fungsi kalimat }\end{array}$ & persuasif \\
\hline $\begin{array}{c}\text { adanya kesalahan } \\
\text { ejaan }\end{array}$ & persuasif \\
\hline $\begin{array}{c}\text { adanya pengaruh } \\
\text { dialek }\end{array}$ & menggugah \\
\hline $\begin{array}{l}\text { adanya dominasi } \\
\text { frase }\end{array}$ & bertenaga gerak \\
\hline $\begin{array}{c}\text { terjadinya } \\
\text { pengabaian } \\
\text { hubungan } \\
\text { sintagmatik }\end{array}$ & menggugah \\
\hline $\begin{array}{l}\text { adanya pengaruh } \\
\text { bahasa asing }\end{array}$ & persuasif \\
\hline ambiguitas & persuasif \\
\hline
\end{tabular}

Berdasarkan realitas penggunaan bahasa iklan pada papan reklame di jalan utama antara Kampung Rambutan sampai dengan Lebak Bulus menunjukkan adanya komposisi aspek kebakuan dan aspek struktur bahasa iklan yang beragam, di samping 
memiliki tingkat kesalahan yang bervariasi. Dari aspek kebakuan bahasa diperoleh data sebagai berikut.

$$
\mid
$$

\begin{tabular}{|c|c|} 
Jumlah Data & Persentase \\
\hline 5 reklame & $28 \%$ \\
3 reklame & $17 \%$ \\
2 reklame & $11 \%$ \\
2 reklame & $11 \%$ \\
2 reklame & $11 \%$ \\
1 reklame & $5,5 \%$ \\
1 reklame & $5,5 \%$ \\
1 reklame & $5,5 \%$ \\
1 reklame & $5,5 \%$ \\
18 reklame & $100 \%$
\end{tabular}

Dengan demikian, aspek kebakuan bahasa iklan pada papan reklame pada jalan utama antara Kampung Rambutan sampai dengan Lebak Bulus dapat dinyatakan memiliki tingkat kebakuan yang sangat rendah. Hanya 5,5\% yang memenuhi kaidah kebakuan bahasa. Di sisi lain, aspek ketidakbakuan bahasa iklan pada papan reklame antara lain: 1) dominasi frase/klausa $28 \%, 2$ ) pengabaian hubungan sintagmatik $17 \%$, 3) pelesapan fungsi kalimat $11 \%$, 4) pengaruh dialek 11\%,5) pengaruh bahasa asing $11 \%, 6)$ kesalahan ejaan 5,5\%,7) ambiguitas 5,5\%, dan 8) pengabaian konjungsi $5,5 \%$. Hal ini berarti, penggunaan bahasa iklan pada papan reklame pada jalan utama antara Kampung Rambutan sampai dengan Lebak Bulus memiliki tingkat kebakuan yang tergolong sangat rendah, hanya mencapai 5,5\%, sedangkan aspek ketidakbakuan bahasa iklan mencapai $94,5 \%$. Struktur bahasa iklan pada papan reklame jalan utama antara kampung rambutan sampai dengan lebak bulus dijabarkan sebagai berikut.

\section{Aspek Struktur}

$$
\mid
$$

Jumlah Data
8 reklame
4 reklame
3 reklame
3 reklame
18 reklame

Persentase
$44 \%$
$22 \%$
$17 \%$
$17 \%$
$100 \%$

Berdasarkan penjabaran di atas, aspek struktur bahasa iklan pada papan reklame pada jalan utama antara Kampung Rambutan sampai dengan Lebak Bulus dapat diklasifikasikan ke dalam bentuk struktur: 1) persuasif $44 \%, 2$ ) bertenaga gerak $22 \%$, 3) menggugah $17 \%$, dan 4) informatif $17 \%$. Hal ini berarti struktur bahasa yang dipakai lebih dominan bersifat persuasif, agar membuat konsumen merasa nyaman, senang, tenteram, dan menghibur. 
Mengacupada teks bahasa iklan pada papan reklame yang terdapat pada jalan utama antara KampungRambutansampaidenganLebakBulus yang menjadi objek penelitian, kemudiandilakukananalisisterhadap satuan bahasa yang digunakan, baik dalam bentuk kata maupun kalimat.

Penggunaan bahasa iklan pada papan reklame yang terdapat pada jalan utama antara Kampung Rambutan sampai dengan Lebak Bulus menunjukkan masih adanya ketidakbakuan atau kesalahan dalam penelitian bahasa iklan yang tergolong besar. Beberapa contoh kesalahan yang terjadi dapat disimak dalam contoh berikut.

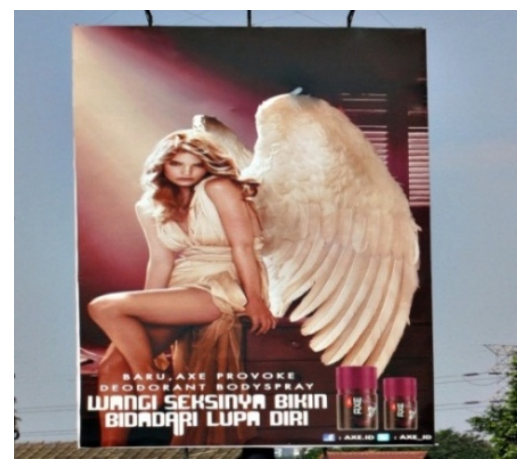

Bahasa iklan pada reklame di samping yang berbunyi WANGI SEKSINYA BIKIN BIDADARI LUPA DIRI menunjukkan adanya pengaruh dialek dengan menggunakan kata "BIKIN" pada teks iklan. Kondisi ini dapat menyebabkan terjadinya ketidakkonsistenan pesan iklan kepada konsumen. Bahasa iklan yang semacam ini dapat diperbaiki menjadi "WANGI SEKSINYA MEMBUAT BIDADARI LUPA DIRI".

Penggunaan bahasa iklan dalam media iklan apapun, termasuk papan reklame harus memuat teks iklan yang memiliki karakteristik, orisinal, dan persuasif. Penggunaan kata-kata atau kalimat dalam bahasa iklan harus disusun dengan kaidah tata bahasa yang lugas dan tidak menimbulkan makna ganda. Di sisi lain, bahasa iklan pun harus terhindar dari gejala bahasa yang dapat menjadikan pesan dan makna iklan menjadi bias. Oleh karena itu, bahasa iklan harus dihindari dari berbagai gejala bahasa yang tidak efektif, seperti penggunaan frase/klausa yang berlebihan, pengabaian hubungan sintagmatik, pelesapan fungsi kalimat, pengaruh dialek, pengaruh bahasa asing, kesalahan ejaan, ambiguitas, dan pengabaian konjungsi. Apabila bahasa iklan tidak baku, tingkat keberterimaan bahasa iklan yang digunakan pada papan reklame tergolong rendah karena tidak didukung oleh kelengkapan kaidah-kaidah bahasa yang baku.

\section{PENUTUP}

Penggunaan bahasa iklanpada papan reklame yang terdapat pada jalan utama antara KampungRambutansampaidenganLebak Bulus dapat disimpulkan sebagai berikut.

1. Aspek kebakuan bahasa iklan pada papan reklame pada jalan utama antara Kampung Rambutan sampai dengan Lebak Bulus memiliki tingkat kebakuan yang sangat rendah, mencapai 5,5\% dan bahasa iklan yang tidak baku mencapai 94,5\%. Aspek ketidakbakuan bahasa iklan pada papan reklame lebih didominasi oleh 1) dominasi pemakaian frase, 2) pengabaian hubungan sintagmatik, 3) adanya pelesapan fungsi kalimat, 4) pengaruh dialek, 5) pengaruh bahasa asing, 6) kesalahan ejaan, 7) ambiguitas, dan 8) pengabaian konjungsi. 
2. Aspek struktur bahasa iklan pada papan reklame pada jalan utama antara Kampung Rambutan sampai dengan Lebak Bulus dapat diklasifikasikan ke dalam bentuk bahasa iklan yang mengandung struktur persuasif sebesar $44 \%$, struktur bertenaga gerak sebesar $22 \%$, struktur menggugah sebesar $17 \%$, dan struktur informatif sebesar $17 \%$. Hal ini berarti struktur bahasa iklan pada papan reklame pada jalan utama antara Kampung Rambutan sampai dengan Lebak Bulus lebih didominasi oleh struktur yang bersifat persuasif yang bertumpu pada penggunaan bahasa iklan yang menyajikan rangkaian kalimat atau kata yang dapat membuat konsumen nyaman, senang, tenteram, dan menghibur.

\section{DAFTAR PUSTAKA}

Arifin, E. Zaenal dkk. 2014. Pengembangan dan Pembinaan Bahasa dalam Era Teknologi Informasi. Tangerang: Pustaka Mandiri.

Jefkins, Frank. 1997. Periklanan. Jakarta: Erlangga.

Kasali, Rhenald. 2007. Manajemen Periklanan: Konsep dan Aplikasinya di Indonesia. Jakarta: Pustaka Utama Grafiti.

Nazir, Moh. 2009. Metode Penelitian. Jakarta: Ghalia Indonesia.

Rachmadi, F. 1993. Public Relation dalam Teori dan Praktik. Jakarta: Gramedia Pustaka Utama.

Rapp, Stan and Tom Collins. 1995. Terobosan Baru dalam Strategi Promosi, Periklanan, dan Promosi. Maxi Marketing. Penerjemah: Hifni Alifahmi. Jakarta: Erlangga.

Ritonga, M. Jamaluddin. 2005. Tipologi Pesan Persuasif. Jakarta: Indeks.

Shimp, Terrence A. 2000. Periklanan dan Promosi Jilid 1. Jakarta: Erlangga.

Suyatno, M. 2004. Aplikasi Desain Grafis untuk Periklanan. Yogyakarta: Andi Offset.

2006. Strategi Perancangan Iklan Outdoor Kelas Dunia. Yogyakarta: Andi

Tim Penyusun Kamus Pusat Pembinaan dan Pengembangan Bahasa. 2008. Kamus Besar Bahasa Indonesia. Edisi Keempat. Jakarta: Balai Pustaka. 
Uturodewo, Felicia N. 2003. Iklan sebagai Media Pembinaan Bahasa Indonesia. Depok: Fakultas Sastra, Universitas Indonesia

Winardi. 1980. Azas-Azas Marketing. Bandung: Alumni. 